\title{
Dry Eye Symptoms in Patients after Eyelid Reconstruction with Full-Thickness Eyelid Defects: Using the Tomey TG-1000 Thermographer
}

\author{
Johannes Gonnermann Julian P. Klein Matthias K.J. Klamann \\ Anna-Karina Maier Uwe Pleyer Antonia M. Joussen Eckart Bertelmann \\ Department of Ophthalmology, Charité, University Medicine Berlin, Berlin, Germany
}

\section{Key Words}

Thermography $\cdot$ Ocular surface temperature $\cdot$ Tomey

TG-1000 • Dry eye $\cdot$ Tarsoconjunctival graft $\cdot$ Full-thickness eyelid defects

\begin{abstract}
Background: Large full-thickness eyelid defects are conventionally reconstructed by either a Hughes flap or CutlerBeard bridge flap. Since the structure of the eyelid and its components are necessary for the tear film production and stability, we investigated the outcome after eyelid reconstruction focusing on dry eye symptoms using a new thermographic device, the TG-1000. Methods: Seventeen eyes of patients formerly treated with Hughes flaps $(n=16)$ and a Cutler-Beard bridge flap $(n=1)$ were compared to untreated healthy eyes $(n=17)$ regarding the functional and aesthetic outcome. The follow-up ranged from 3 to 63 months (mean $24.88 \pm 17.86)$. Results: There was no significant difference in Schirmer's test, break-up time and ocular surface temperature $(p>0.05)$ between patients after full-thickness eyelid reconstruction and a control group. Eleven patients had minor postoperative complications such as notching of the lid margin (11/17), epiphora (1/17), superficial punctate keratitis $(6 / 17)$, trichiasis (2/17) and a mild tendency to eversion of the lid margin (6/17). More than $75 \%$ of the patients rated their
\end{abstract}

postoperative aesthetic outcome as good or even excellent. Conclusion: The new TG-1000 device is a simple and quick tool for screening of dry eye. This study shows that tarsoconjunctival grafts offer good aesthetic and functional outcome with sufficient tear film composition and stability.

Copyright $\odot 2012$ S. Karger AG, Basel

\section{Introduction}

The chief function of the upper and lower eyelids is to protect the cornea. Therefore in all cases, the primary objective of the reconstruction of full-thickness eyelid defects is an adequate corneal protection and preservation of vision, with good aesthetic outcome and symmetry as a secondary consideration [1]. Full-thickness defects greater than $50 \%$ of the horizontal length of the upper or lower eyelid are often reconstructed by either Hughes or Cutler-Beard bridge flaps [2, 3]. This can induce either major complications, including marked upper lid retraction after upper lid reconstruction, wound dehiscence, entropion, ectropion and excessive lower lid

This work was presented at the ARVO Meeting 2011, Fort Lauderdale, USA, April 30 to May 3, 2011.

\section{KARGER}

Fax +4161306 1234

E-Mail karger@karger.ch

www.karger.com (c) 2012 S. Karger AG, Basel

$0030-3747 / 12 / 0484-0192 \$ 38.00 / 0$

Accessible online at:

www.karger.com/ore
Johannes Gonnermann, MD

Department of Ophthalmology, University Medicine Charité Berlin Augustenburger Platz 1

DE-13353 Berlin (Germany)

Tel. +49 30450654 229, E-Mail johannes.gonnermann@charite.de 
laxity, or minor complications, such as trichiasis, notching or mild eversion and inversion of the lid margin, symblepharon and corneal irritation with dry eye symptoms including punctate keratitis, epiphora, pain, redness, burning and foreign body sensation [4].

In diagnosing dry eye symptoms, tear dynamics are currently evaluated clinically by Schirmer's test, break-up time (BUT), inspection of lids and conjunctiva (lid-parallel conjunctival folds), measurement of the tear meniscus, osmolarity testing and the rose Bengal test [5-8]. First reports demonstrated that the measurement of the corneal surface temperature may complement the diagnostic tools [9-13]. Ocular surface thermography is a well-known technique for temperature measurement of the anterior eye. Modern thermography, pioneered by Mapstone [12], is a non-invasive technique used to measure the surface temperature of an object by detecting the intensity of infrared light that is emitted from the object. Recently, Tomey presented a new non-contact thermographic infrared light device (Tomey TG-1000, Tomey Germany, Erlangen, Germany). The current instrumentation offers the potential to measure the ocular surface temperature with more accuracy, resolution and speed than previously possible. Kamao et al. [9] showed that the non-invasive measurement with Tomey TG-1000 is a simple and quick tool for screening of dry eye enabling data to be collected quickly, objectively and non-invasively with high intra-observer reproducibility.

Within this article we focus on the aesthetic and functional outcome and especially on dry eye symptoms after eyelid reconstruction of full-thickness eyelid defects using Hughes or Cutler-Beard bridge flaps.

\section{Patients and Methods}

\section{Study Protocol}

All 64 cases of full-thickness eyelid reconstruction after tumour excision over a 5-year period (March 2005 to March 2010) at Charité University Hospital Berlin were identified from the operating theatre logbook and reviewed. The Hughes and CutlerBeard bridge flaps were only performed in patients with fullthickness eyelid defects greater than $50 \%$ of the horizontal length of the upper or lower eyelid. Since we do not have any financial interest in the instrument, only patients living within a $10-\mathrm{km}$ radius from the hospital were re-examined because no refund of transportation costs could be provided.

Nevertheless, 17 eyes of 17 patients (10 women and 7 men; mean age \pm standard deviation, $69.12 \pm 7.59$ years) treated with surgery enclosing Hughes flaps $(\mathrm{n}=16)$ and a Cutler-Beard bridge flap ( $n=1)$ from March 2005 to March 2010 were included in this study and compared to their untreated healthy eyes focusing on dry eye symptoms retrospectively. The healthy eyes had neither ocular pathology nor corneal inflammatory signs. The subjects were not applying topical eye medication or using contact lenses and did not suffer from dry eye symptoms.

All patients were operated after histologically tumour-free resection margins by the same surgeon. Four weeks after lid reconstruction the standardized re-opening of the eyelid was carried out. The follow-up after surgery ranged from 3 to 63 months (mean $24.88 \pm 17.86$ ). The ocular surface temperature was measured by new Tomey TG-1000 thermography. The aesthetic result and complications were documented, and digital colour images were taken by the photo device of Tomey TG-1000. Complications were divided into major and minor complications. As major complications were considered marked upper lid retraction after upper lid reconstruction, wound dehiscence, entropion, ectropion and excessive lower lid laxity. Minor complications were classified as notching or mild eversion and inversion of the lid margin, trichiasis, symblepharon and corneal irritation with dry eye symptoms including punctate keratitis, epiphora, pain, redness, burning and foreign body sensation. Afterwards the tear film was evaluated using Schirmer's test and fluorescein tear film BUT. Additionally, the patients filled out a questionnaire based on the National Eye Institute Visional Functioning Questionnaire 25 to estimate their satisfaction with the aesthetic und functional outcome.

\section{Thermography}

A newly developed non-contact thermography device (Tomey TG-1000, Tomey Corp., Nagoya, Japan) was used. Kamao et al. [9] first described this ocular surface thermographer. The instrument is equipped with an infrared camera module (HX083M1; NEC, Tokyo, Japan) and a colour charged coupled device board camera (PKD-101; Pacific Co., Tokyo, Japan). Light can be directed into either an infrared camera or visible light camera. The direction of the light is changed by a rotating mirror, and both infrared and visible light images can be recorded co-axially. This instrument ought to detect temperatures in a target range between 30 and $40^{\circ} \mathrm{C}$, with a minimum temperature accuracy of $\pm 0.1^{\circ} \mathrm{C}$. The frame rate of 4 frames a second was denoted, which means 2 frames a second each when measuring infrared and colour images at the same time. Ten seconds were required to perform each measurement. Using the highest magnification, the infrared sensor can record images at a resolution of $320 \times 240$ pixels with a pixel size of $23.5 \times 23.5 \mu \mathrm{m}$ and spatial resolution of 70 $\mu \mathrm{m}$. The infrared radiation detector module is sensitive to infrared radiation between 8 and $14 \mu \mathrm{m}$. Colour images are obtained with a coupled device video camera that can record images at a resolution of $640 \times 480$ pixels, pixel size $5.6 \times 5.6 \mu \mathrm{m}$, and a detection range of $0.5 \mathrm{~lx}$ at $1 / 30 \mathrm{frames} / \mathrm{s}$. To correct for background radiation entering the infrared camera, a black body plate is inserted automatically to cover the sensor immediately before beginning the measurements. To correct for changes in the temperature of the interior of the instrument during the measurements, a sensor was embedded in the camera and a program was installed in the instrument to correct for changes in the internal temperature. An auto-alignment function is incorporated in the instrument to ensure that the instrument and object are maintained in a fixed location relative to each other. With this autoalignment function, the position of the cameras with respect to the object to be measured can be held constant, which allows measurements of the ocular surface temperature to be performed at the same position. There is virtually no human error involved in 
Fig. 1. Screenshot of an ocular surface temperature measurement with the Tomey TG-1000. Temperature is given in degrees Celsius. Infrared image and picture photograph are shown top left. The lower eyelid was reconstructed with a Hughes bridge flap in June 2005. Infrared images over $10 \mathrm{~s}$ of eye opening at the bottom.

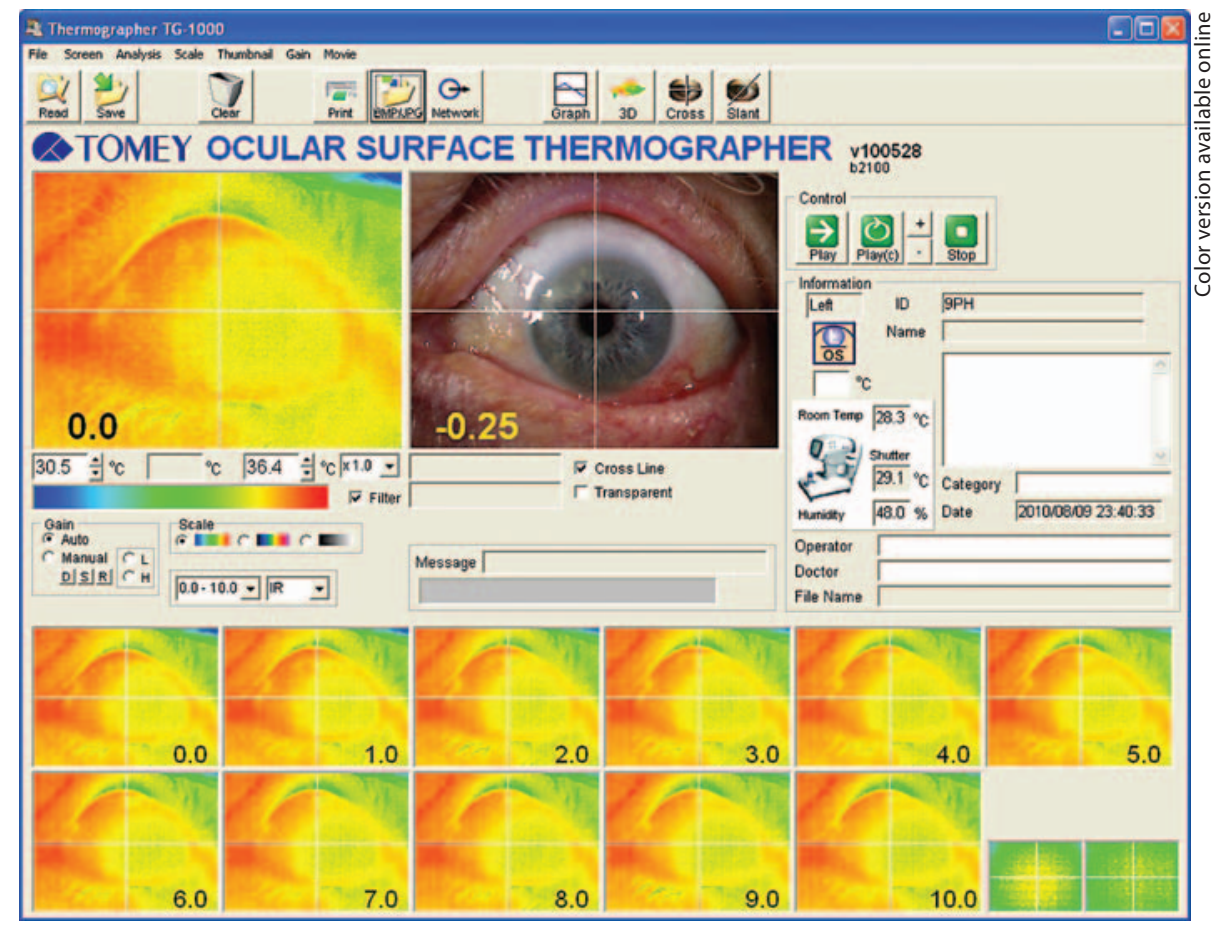

operating the ocular surface thermographer. This feature is identical to that of the RC-5000 Autorefractor/Keratometer (RC-5000; Tomey Corp.), which recognizes the pupil and aligns the pupil in the centre of the screen when the examiner touches the centre of the touch panel. The head of the ocular surface thermographer also moves along the $\mathrm{z}$-axis automatically to maintain the instrument at a fixed distance from the eye.

Each subject was examined in a room at $24.0 \pm 1.5^{\circ} \mathrm{C}$, with standard indoor levels of illumination and no air drafts. The measurements were performed under the conditions described by Mori et al. [11]: the subject blinked normally, then closed both eyes for $5 \mathrm{~s}$, and then kept the eyes open for more than $10 \mathrm{~s}$. The thermography device was set up $20 \mathrm{~cm}$ in front of the eye, and the head was held steady by a head-holder frame. First, the subject was instructed to open his eyes naturally and look straight ahead to get a sharp image of the cornea at the implemented monitor. After that, the subject was asked to close the eyes. Now with closed eyes, the surrounding temperature of the ocular surface including the surrounding tissue and the overall room temperature were measured within $5 \mathrm{~s}$. Afterwards, the subjects were requested to open both eyes naturally and look straight ahead again, and after a blink, a measurement was made. The temperature was measured within $10 \mathrm{~s}$ of opening the eye. During that time the subject was asked not to blink. If the subject blinked anyway, a new measurement was performed.

To avoid any unsteadiness, all thermographic measurements were performed in an examination room used for ocular thermography by one examiner.

Following these investigations all images were converted to infrared and colour pictures and were made visible on a monitor for analysing. Minimum and maximum temperature readings as well as the temperature over the course of the $10 \mathrm{~s}$ of eye opening were given in graphical order. Special points of interest of the ocular surface could be selected by moving a cross on the colour or infrared picture. At these selected points the temperature data were given as mentioned.

Representative examples of ocular surface temperature measurements are shown in figures 1-3.

\section{Schirmer's Test without and with Anaesthesia}

Schirmer's test without anaesthesia was performed by lightly dabbing the inferior fornix with a cotton tip applicator to remove excess tears, bending the Schirmer strip at the notch, and placing the strip beneath the temporal lid margin with the notch at the lid margin. The patient was then instructed to close the eyelids gently, not to speak or make facial expressions that could result in the movement of the facial musculature, and to position the chin on the chin rest of the slit lamp. This was done to maintain the subject's head in an erect position. The subject was also instructed not to move the eyes in order to minimize or avoid contact between the cornea and Schirmer's test paper. All of the above precautions were taken to minimize reflex tearing. Schirmer's test results were then recorded after $5 \mathrm{~min}$. The wet portion of the litmus paper was measured in millimetres per 5 min.

Fifteen minutes later, Schirmer's test was performed with one drop of topical anaesthetic (Conjuncain ${ }^{\circledR}$, EDO) to measure the basic secretion rate.

\section{Measurement of Fluorescein BUT}

The BUT is an indirect measure of tear film stability with instability indicated by a BUT of $<10 \mathrm{~s}$. The BUT was measured following a 15 -min rest interval using $2 \%$ sodium fluorescein solution that was instilled onto the inferior palpebral conjunctiva after gentle depression of the lower eyelid. The subject was then 
Fig. 2. Screenshot of an ocular surface temperature measurement with the Tomey TG-1000. Same subject as in figure 1 . Average temperature during $10 \mathrm{~s}$ of eye opening in a graphical order top right. Almost horizontal course of the temperature line in a stable tear layer.

Fig. 3. Screenshot of an ocular surface temperature measurement with the Tomey TG-1000. Average temperature during $10 \mathrm{~s}$ of eye opening in a graphical order top right. Sloping course of the temperature line in an unstable tear layer, may be due to dry eye syndrome, in this case without any subjective complaints. The lower eyelid was reconstructed with a Hughes bridge flap in October 2005.
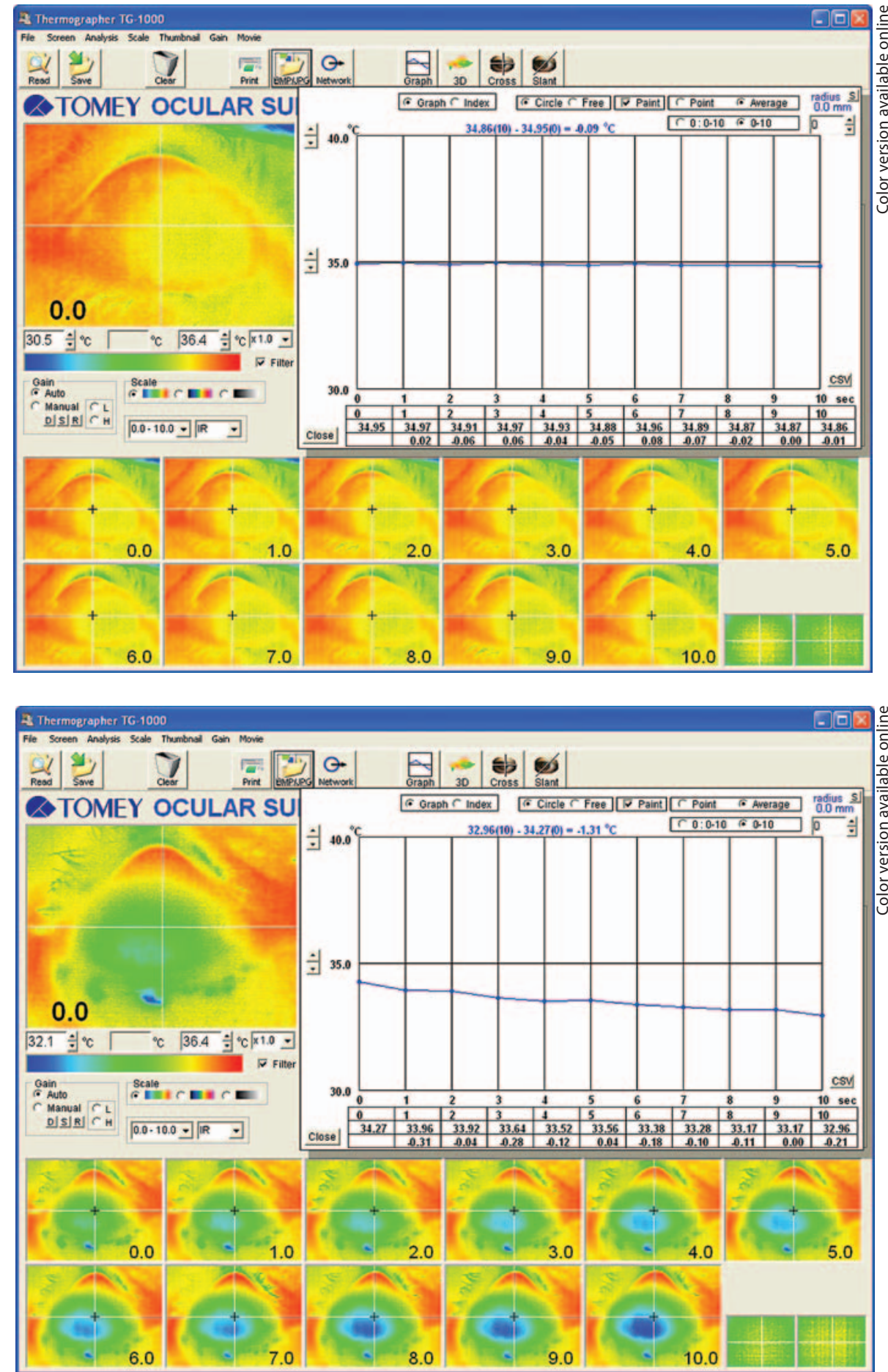

asked to blink gently, but completely, 3 times. The tear film was then examined with a broad beam and the cobalt blue filter of a slit lamp. The interval between the last blink and the appearance of the first precorneal hypofluorescent spot, streak or other irregularity interrupting the normal homogenous fluorescein pattern was recorded as the BUT (seconds).

\section{Statistics}

All eyes ( $\mathrm{n}=34$ ) of the subjects were included in the analysis. Statistical analysis was conducted with the analysis program PAWS (version 18.0, version for Mac). In all groups, non-parametric distribution of the data was found (Kolmogorow-Smirnow test). Parameters of interest were statistically compared between 
groups using the Mann-Whitney $U$ Wilcoxon rank sum test. The level of significance was set at $\mathrm{p}<0.05$.

Statement of Ethics

We certify that all applicable institutional and governmental regulations concerning the ethical use of human volunteers were followed during this research.

\section{Results}

Table 1 shows the means and standard deviations of minimal and maximal ocular surface temperature and temperature gradient between eyes after full-thickness eyelid reconstruction and a control group. Even though the mean gradient of ocular surface temperature ( $\mathrm{p}=$ $0.586)$ after $10 \mathrm{~s}$ of eye opening and minimal $(\mathrm{p}=0.708)$ and maximal $(\mathrm{p}=0.786)$ ocular surface temperature were lower in the group with reconstructed eyelids, no significant difference could be found. Accordingly there was neither a significant difference in Schirmer's test with $(\mathrm{p}=0.865)$ and without $(\mathrm{p}=0.339)$ anaesthesia nor BUT $(\mathrm{p}=0.067$; table 2$)$.

After surgery $64.7 \%$ of the patients had minor complications such as notching of the lid margin (11/17), trichiasis $(2 / 17)$, epiphora (1/17), superficial punctate keratitis $(6 / 17)$ and a mild tendency to eversion of the lid margin $(6 / 17)$ which did not require revision. No major complications could be seen. The patient satisfaction rate with the aesthetic outcome after reconstruction of full-thickness eyelid defects was very good. More than 75\% of the patients rated their aesthetic appearance good or even excellent after surgery (table 3 ).

\section{Discussion}

Compared to formal devices, TG-1000, the latest commercially available generation of ocular surface thermographers, has several advantages. Including an infrared sensor with a dissolution of $320 \times 240$ pixels and an infrared wavelength range between 8 and $14 \mu \mathrm{m}$, the measurement of the ocular surface leads to a high dissolving colour-coded infrared image. Therefore, the ocular surface thermographer is able to perform measurements in the same manner as a standard autorefractor/keratometer with an auto-alignment function, enabling data to be collected quickly, objectively and non-invasively with high intra-observer reproducibility $[9,13]$. Secondary to a photo picture, the ocular surface thermographer displays visible light and thermal images simultaneously.
Table 1. Means and standard deviations of maximal and minimal ocular surface temperature (OST) and temperature gradient $\left({ }^{\circ} \mathrm{C}\right)$ between patients with reconstructed eyelids and the control group

\begin{tabular}{llll}
\hline Study group & $\begin{array}{l}\text { Minimal } \\
\text { OST }\end{array}$ & $\begin{array}{l}\text { Maximal } \\
\text { OST }\end{array}$ & $\begin{array}{l}\text { Gradient of } \\
\text { OST after 10 s }\end{array}$ \\
\hline $\begin{array}{c}\text { Reconstructed eyelid } \\
(\mathrm{n}=17)\end{array}$ & $34.32 \pm 1.07$ & $34.73 \pm 0.84$ & $-0.04 \pm 0.54$ \\
$\begin{array}{c}\text { Control group } \\
(\mathrm{n}=17)\end{array}$ & $34.49 \pm 0.78$ & $34.82 \pm 0.59$ & $-0.09 \pm 0.47$ \\
\hline
\end{tabular}

$\mathrm{p}>0.05$, no significant difference.

Table 2. Means and standard deviations of Schirmer's test with/ without anaesthesia and BUT between patients with reconstructed eyelids and the control group

\begin{tabular}{llll}
\hline Study group & $\begin{array}{l}\text { Schirmer's test } \\
\text { without } \\
\text { anaesthesia, mm }\end{array}$ & $\begin{array}{l}\text { Schirmer's } \\
\text { test with anaes- } \\
\text { thesia, mm }\end{array}$ & $\begin{array}{l}\text { BUT } \\
\text { (fluores- } \\
\text { cein), } s\end{array}$ \\
\hline $\begin{array}{l}\text { Reconstructed eyelid } \\
(\mathrm{n}=17)\end{array}$ & $14.53 \pm 9.95$ & $19.71 \pm 11.60$ & $9.59 \pm 4.05$ \\
$\begin{array}{l}\text { Control group } \\
(\mathrm{n}=17)\end{array}$ & $16.12 \pm 11.35$ & $23.00 \pm 9.87$ & $12.12 \pm 4.05$ \\
\hline $\mathrm{p}>0.05$, no significant difference. & & \\
\hline
\end{tabular}

Table 3. Patient satisfaction (\%) with aesthetic outcome after reconstruction of full-thickness eyelid defects

\begin{tabular}{llllll}
\hline & Excellent & Good & Fair & Poor & Very poor \\
\hline Patients $(\mathrm{n}=17)$ & 35.4 & 41.2 & 17.6 & 5.8 & 0 \\
\hline
\end{tabular}

Therefore regions of the thermal image can easily and accurately be compared to real ocular conditions [9]. Additionally, this kind of repetition gives the opportunity to document changes in both temperature and anatomy in an easy way. This possibility is very helpful in many diseases of the ocular surface [14], e.g. in screening for dry eye symptoms after full-thickness eyelid reconstruction.

Patients with dry eyes show an altered tear film layer $[5,15,16]$. The most common cause of dry eye syndrome is decreased production of the lipid layer (from meibomian glands), which results in destabilization and evapo- 
ration of the tear film [6]. As reported by Fujishima et al. [10] evaporation of tears reduces the temperature of the surface. In a study of normal subjects, Purslow and Wolffsohn [17] observed that the ocular surface temperature variation for $8 \mathrm{~s}$ immediately after a blink is better related to tear film properties than other physical characteristics of the anterior eye. They observed a strong correlation between initial post-blink ocular surface temperature and tear film stability as assessed by non-invasive BUT, with ocular surface temperature decreasing as noninvasive BUT increases. Therefore, the temperature gradient is the crucial parameter analysing the evaporation from the eye surface, especially in dry eye symptoms [18, 19]. In previous studies a significant negative correlation between temperature gradient at the centre of the cornea and BUT could be found in patients with dry eyes [9]. This indicates that eyes with a shorter BUT are more likely to have a decrease in ocular surface temperature.

It is a well-known fact that elective eyelid surgery may mechanically alter the corneoscleral and conjunctival interface sufficiently to aggravate or unmask dry eye symptoms [20, 21]. However, little has been mentioned regarding the possible complications associated with the use of tarsoconjunctival grafts to reconstruct full-thickness eyelid defects.

In our study the functional and aesthetic outcomes after tarsoconjunctival grafting were generally satisfactory throughout a 5 -year follow-up. $64.7 \%$ of our patients had minor complications such as notching of the lid margin (11/17), trichiasis (2/17), epiphora (1/17), superficial punctate keratitis (6/17) and a mild tendency to ectropion (6/17) which did not require revision. This accords with previously published studies $[2,4,22]$. We did not see any major complications that would have required revision. More than $75 \%$ of the patients rated their aesthetic outcome as good or even excellent after surgery.

Analysing dry eye symptoms, Schirmer's test without $(14.53 \pm 9.95 \mathrm{~mm})$ and with $(19.71 \pm 11.60 \mathrm{~mm})$ anaes- thesia as well as BUT $(9.59 \pm 4.05 \mathrm{~s})$ were lower in reconstructed eyelids compared to the control group. These findings were not statistically significant $(p>0.05)$ and in agreement with the measurements of the ocular surface thermography. Even though the mean gradient of ocular surface temperature $\left(-0.04 \pm 0.54^{\circ} \mathrm{C}\right)$ after $10 \mathrm{~s}$ of eye opening and minimal $\left(34.32 \pm 1.07^{\circ} \mathrm{C}\right)$ and maximal $\left(34.73 \pm 0.84^{\circ} \mathrm{C}\right)$ ocular surface temperatures were also lower in the group with reconstructed eyelids, no significant difference could be found.

In summary, the new TG-1000 could be a simple, noninvasive and quick tool for screening of dry eye syndrome. Temperature is one of the fundamental characteristics of tissue metabolism and is certainly of major interest to investigate ocular physiology and especially pathophysiology of dry eye symptoms. Ocular surface thermography has several advantages to other dry eye tests. Compared to impression cytology, the device gives objectively measurements without being invasive, painful and time consuming. The downside to ocular surface thermography is its price. This study shows that despite frequent minor complications and occasional major complications the use of tarsoconjunctival grafts offers a good aesthetic and functional outcome with sufficient tear film composition and stability. To the best of our knowledge, this is the first paper focusing on these factors after reconstructive eyelid surgery. Tarsoconjunctival grafting remains a valuable procedure in the surgeon's choice for reconstruction of major eyelid defects. To evaluate alternatives in eyelid reconstruction, further investigation regarding tear film composition and stability using TG1000 need to be done.

\section{Disclosure Statement}

There is no conflict of interest to declare.

\section{References}

Dry Eye after Eyelid Reconstruction
1 Verity DH, Collin JR: Eyelid reconstruction: the state of the art. Curr Opin Otolaryngol Head Neck Surg 2004;12:344-348.

-2 Herde J, Krause A, Bau V: Results of the Hughes operation (in German). Ophthalmologe 2001;98:472-476.

3 Bertelmann E, Rieck P: Relapses after surgical treatment of ocular adnexal basal cell carcinomas: 5-year follow-up at the same university centre. Acta Ophthalmol 2010, Epub ahead of print.
4 Hawes MJ, Jamell GA: Complications of tarsoconjunctival grafts. Ophthal Plast Reconstr Surg 1996;12:45-50.

5 Craig JP, Singh I, Tomlinson A, Morgan PB, Efron N: The role of tear physiology in ocular surface temperature. Eye (Lond) 2000;14: 635-641.

6 Foulks GN: The correlation between the tear film lipid layer and dry eye disease. Surv Ophthalmol 2007;52:369-374. 
7 Versura P, Profazio V, Campos EC: Performance of tear osmolarity compared to previous diagnostic tests for dry eye diseases. Curr Eye Res 2010;35:553-564.

$\checkmark 8$ Hoh H, Schirra F, Kienecker C, Ruprecht KW: Lid-parallel conjunctival folds are a sure diagnostic sign of dry eye (in German). Ophthalmologe 1995;92:802-808.

-9 Kamao T, Yamaguchi M, Kawasaki S, Mizoue S, Shiraishi A, Ohashi Y: Screening for dry eye with newly developed ocular surface thermographer. Am J Ophthalmol 2011; 151:782-791.

10 Fujishima H, Toda I, Yamada M, Sato N, Tsubota K: Corneal temperature in patients with dry eye evaluated by infrared radiation thermometry. Br J Ophthalmol 1996;80:2932.

11 Mori A, Oguchi Y, Okusawa Y, Ono M, Fujishima $\mathrm{H}$, Tsubota K: Use of high-speed, high-resolution thermography to evaluate the tear film layer. Am J Ophthalmol 1992; 124:729-735.
12 Mapstone R: Measurement of corneal temperature. Exp Eye Res 1968;7:237-243.

13 Klamann MK, Maier AK, Gonnermann J, Klein JP, Pleyer U: Measurement of dynamic ocular surface temperature in healthy subjects using a new thermography device. Curr Eye Res 2012, E-pub ahead of print.

14 Klamann MK, Klein JP, Maier AK, Gonnermann J, Pleyer U: Application possibilities of modern thermography - first experiences with the new Tomey TG 1000 (in German). Klin Monatsbl Augenheilkd 2011;228:515519.

15 Peral A, Dominguez-Godinez CO, Carracedo G, Pintor J: Therapeutic targets in dry eye syndrome. Drug News Perspect 2008;21: 166-176.

16 Farris RL: The dry eye: its mechanisms and therapy, with evidence that contact lens is a cause. CLAO J 1986;12:234-246.

17 Purslow C, Wolffsohn J: The relation between physical properties of the anterior eye and ocular surface temperature. Optom Vis Sci 2007;84:197-201.
8 Morgan PB, Soh MP, Efron N, et al: Potential applications of ocular thermography. Optom Vis Sci 1993;70:568-576.

19 Morgan PB, Tullo AB, Efron N: Infrared thermography of the tear film in dry eye. Eye (Lond) 1995;9:615-618.

20 Rees TD, LaTrenta GS: The role of the Schirmer's test and orbital morphology in predicting dry-eye syndrome after blepharoplasty. Plast Reconstr Surg 1988;82:619-625.

21 McKinney P, Byun M: The value of tear film breakup and Schirmer's tests in preoperative blepharoplasty evaluation. Plast Reconstr Surg 1999;104:566-569, discussion 570-573.

22 Engelmann V, Pfrommer S, Dridi MJ, Piening J, Lohmann CP, Merté RL: Comparison of the aesthetic outcome and complication rate of reconstructive surgical procedures of the eyelid after basalioma excision (in German). Ophthalmologe 2011;108:33-37. 